Research Paper

\title{
Specific Pyruvate Kinase M2 Inhibitor, Compound 3K, Induces Autophagic Cell Death through Disruption of the Glycolysis Pathway in Ovarian Cancer Cells
}

\author{
Jae Hyeon Park, Amit Kundu, Su Hyun Lee, ChunXue Jiang, Song Hee Lee, Ye Seul Kim, So Young Kyung, \\ So Hyun Park, Hyung Sik Kim ${ }^{凶}$ \\ School of Pharmacy, Sungkyunkwan University, Suwon 16419, Republic of Korea. \\ $\triangle$ Corresponding author: Hyung Sik Kim, E-mail: hkims@skku.edu. \\ (c) The author(s). This is an open access article distributed under the terms of the Creative Commons Attribution License (https://creativecommons.org/licenses/by/4.0/). \\ See http:/ /ivyspring.com/terms for full terms and conditions.
}

Received: 2021.02.26; Accepted: 2021.04.23; Published: 2021.05.05

\begin{abstract}
Ovarian cancer is a common cause of death among gynecological cancers. Although ovarian cancer initially responds to chemotherapy, frequent recurrence in patients remains a therapeutic challenge. Pyruvate kinase M2 (PKM2) plays a pivotal role in regulating cancer cell survival. However, its therapeutic role remains unclear. Here, we investigated the anticancer effects of compound $3 \mathrm{~K}$, a specific PKM2 inhibitor, on the regulation of autophagic and apoptotic pathways in SK-OV-3 (PKM2-overexpressing human ovarian adenocarcinoma cell line). The anticancer effect of compound $3 \mathrm{~K}$ was examined using MTT and colony formation assays in SK-OV-3 cells. PKM2 expression was positively correlated with the severity of the tumor, and expression of pro-apoptotic proteins increased in SK-OV-3 cells following compound $3 \mathrm{~K}$ treatment. Compound $3 \mathrm{~K}$ induced AMPK activation, which was accompanied by mTOR inhibition. Additionally, this compound inhibited glycolysis, resulting in reduced proliferation of SK-OV-3 cells. Compound $3 \mathrm{~K}$ treatment suppressed tumor progression in an in vivo xenograft model. Our findings suggest that the inhibition of PKM2 by compound $3 \mathrm{~K}$ affected the Warburg effect and induced autophagic cell death. Therefore, use of specific PKM2 inhibitors to block the glycolytic pathway and target cancer cell metabolism represents a promising therapeutic approach for treating PKM2-overexpressing ovarian cancer.
\end{abstract}

Key words: compound 3K, ovarian cancer, pyruvate kinase M2, autophagy, apoptosis

\section{Introduction}

Ovarian cancer is the most common gynecologic tumor of the female reproductive tract. In 2019, approximately 22,530 new cases of ovarian cancer were reported in the United States. Among females, ovarian cancer represents $5 \%$ of the total number of cancer-related deaths in the United States [1]. Due to the lack of specific symptoms, ovarian cancer is often diagnosed at the metastatic stage, contributing to poor prognosis. Although most patients with ovarian cancer initially respond to standard therapies based on a combination of platinum-based chemotherapy and surgery, many patients develop resistance to chemotherapy and present with recurrent tumors. Therefore, the relative 10-year survival rate of ovarian cancer is $8 \%$ for stage IV [2].
In general, cancer cells use a high amount of glucose and secrete a large amount of lactate in the presence of abundant oxygen, in a phenomenon referred to as the "Warburg effect." Glycolytic intermediates produced through the Warburg effect promote the biosynthesis of ATP and cellular macromolecular building blocks [3]. Pyruvate kinase M2 (PKM2), the rate-limiting enzyme in the terminal step of glycolysis, plays one of the most important roles in the aerobic glycolysis pathway, which mediates the conversion of phosphoenolpyruvate to pyruvate to release energy, and thus, it provides favorable conditions for the growth of cancer cells [4].

Besides metabolic reprograming, PKM2 acts as a protein kinase transcriptional coactivator of genes 
that influence cell proliferation, apoptosis, and migration $[5,6]$. In the cellular environment, PKM2 is mechanistically associated with the mammalian target of rapamycin (mTOR)/protein kinase B (Akt) signaling pathway, which is associated with various cellular processes, including cell survival and growth, protein synthesis, cell cycle progression, and angiogenesis [7].

A previous study demonstrated that the overexpression of PKM2 activates mTORC1 by phosphorylating its substrate, AKT1 substrate 1, which in turn accelerates autophagy inhibition and oncogenic growth in cancer cells, leading to poor patient outcome [8]. It has been demonstrated that autophagy is impaired by the activation of the Akt/ mTOR pathway in ovarian cancer cells. Therefore, autophagy is heavily regulated by the kinase mTOR [9].

It has been established that the downregulation of PKM2 reduces cancer growth and induces cell death [10]. The inhibition of PKM2 affects cell survival and proliferation in many types of cancer cells. Peptide aptamers and RNA interference-mediated ablation of PKM2 exerted an anticancer effect through the induction of the apoptosis pathway and sensitization to chemotherapy [11-13]. A recent study reported the anticancer effect of small interfering pyruvate kinase M2 (siPKM2) against SK-OV-3 cell lines in which PKM2 is notably expressed and demonstrated that siPKM2 significantly reduced cell proliferation and induced apoptosis [14]. However, specific PKM2 inhibitors, which can easily be used in clinical settings, have not been investigated in ovarian cancer.

Several PKM2 inhibitors, such as shikonin, metformin, vitamin $\mathrm{K}$, and temozolomide have been reported [9]. Recently, the biological effects of novel naphthoquinone derivatives as selective inhibitors of PKM2 were reported. Some compounds, such as compound 3K, exhibited more potent PKM2 inhibition than shikonin, the conventional PKM2 inhibitor. Compound $3 \mathrm{~K}$ also showed significant antiproliferative activity in various cancer cell lines. The higher selectivity of compound $3 \mathrm{~K} \quad\left(\mathrm{IC}_{50}\right.$ [PKM1]/ $\left.\mathrm{IC}_{50}[\mathrm{PKM} 2]=5.7\right)$ for PKM2 compared with that of the conventional PKM2 inhibitor, shikonin $\left(\mathrm{IC}_{50}[\mathrm{PKM} 1] / \mathrm{IC}_{50}[\mathrm{PKM} 2]=1.5\right)$, was validated using cell-free fluorescent lactate dehydrogenase (LDH) and pyruvate kinase (PK) coupled assay [15].

Several studies have explored the tumorigenic role of PKM2 toward the development of potential treatment strategies for various cancers [11-14, 16, 17]. However, the therapeutic efficacy of the specific PKM2 inhibitor, compound $3 \mathrm{~K}$, in ovarian cancer remains unclear. In this study, we identified a relationship between PKM2 overexpression and ovarian cancer progression. We evaluated the anticancer effects of compound $3 \mathrm{~K}$ in PKM2overexpressing SK-OV-3 cells, a well-established human epithelial adenocarcinoma cell line model that is resistant to several cytotoxic drugs such as cisplatinum, diphtheria toxin, and adriamycin [18]. The inhibition of PKM2 perturbed the glycolytic pathway and activated autophagic cell death by regulating the Akt/AMPK/mTOR pathway. These results suggest that the inhibition of PKM2 can enhance the inhibition of ovarian cancer cell growth by suppressing aerobic glycolysis, which provides a basis for the development of PKM2-targeted therapies for ovarian cancer through PKM2 overexpression.

\section{Materials and Methods}

\section{Reagents}

Compound $3 \mathrm{~K}$ was obtained from SelleckChem (Houston, TX, USA). A solution of compound 3K $(15 \mathrm{mM})$ was prepared in DMSO. Culture medium and fetal bovine serum (FBS) were obtained from Gibco Invitrogen Corporation (Carlsbad, CA, USA). Horseradish peroxidase (HRP)conjugated secondary antibodies were obtained from Santa Cruz Biotechnology (Santa Cruz, CA, USA). Primary antibodies against PKM2, PKM1, Cyclin B1, p-Cdc2, Cdc2, Bax, Bcl-2, caspase 3, Beclin-1, LC3B, Atg5, Atg7, p62, MMP-2, MMP-9, TIMP-2, p-AKT, AKT, p-AMPK, AMPK, p-mTOR, mTOR, p-p70S6K, p70S6K, GLUT1, LDHA, MCT4, and $\beta$-actin were all obtained from Cell Signaling (Beverly, MA, USA). MTT and DAPI were obtained from Thermo Fisher Scientific (Invitrogen, NY, USA).

\section{Cell lines and cell culture}

Human ovarian cancer cell lines (SK-OV-3, CAOV-3, OVCAR3, and TOV-21G) were purchased from the American Type Culture Collection (Manassas, VA, USA). SK-OV-3, CA-OV-3, OVCAR3, and TOV-21G cells were grown in Roswell Park Memorial Institute (RPMI) 1640 supplemented with 10\% FBS, $100 \mathrm{U} / \mathrm{ml}$ penicillin, and $100 \mu \mathrm{g} / \mathrm{ml}$ streptomycin (WelGENE, Daegu, South Korea) in a humidified atmosphere of $5 \% \mathrm{CO}_{2}$ at $37^{\circ} \mathrm{C}$.

\section{Ovarian tissue microarray and immunohisto- chemistry (IHC)}

Tissue microarray (consisting of 18 normal human ovarian and 143 ovarian adenocarcinoma samples) was purchased from US Biomax Inc. (Rockville, MD, USA) (Table 1). IHC analysis was performed to investigate the expression of PKM2 in the normal ovarian and ovarian adenocarcinoma tissue samples. The tissue microarray was treated 
with xylene and graded ethanol, followed by boiling in sodium citrate buffer for $15 \mathrm{~min}$. The slide was treated with $5 \% \mathrm{H}_{2} \mathrm{O}_{2}$ for $15 \mathrm{~min}$, and then with PKM2 antibody (Cat. no. 4053, dilution, 1:1,000; Cell Signaling Technology, Inc., Danvers, MA, USA) for 24 $\mathrm{h}$ at $4{ }^{\circ} \mathrm{C}$. The slides were treated with goat anti-rabbit IgG secondary antibody (VECTOR laboratories, Burlingame, CA, USA) for $30 \mathrm{~min}$, followed by treatment with the HRP-streptavidin reagent (VECTOR laboratories) for $30 \mathrm{~min}$. After staining with DAB (Dako, Agilent, Santa Clara, CA, USA) and subsequently with hematoxylin (Dako), the slides were fixed in the mounting solution after treatment with graded ethanol and xylene. The slides were viewed using a K1-fluo microscope (Nanoscope Systems, Daejeon, Korea) at $200 \times$ magnification. For the histological review, all tissue samples were evaluated by two pathologists. The average immunostaining intensity of PKM2 was determined using a four-category scale: 0 for negative staining, 1 for weak intensity, 2 for moderate intensity, and 3 for strong intensity. The percentage of cells with positive PKM2 immunostaining was calculated (range 0-100). The score for the proportion of stained cells and that for the corresponding intensity of staining were added to obtain the total PKM2 immunostaining score (range 0-300).

\section{Cytotoxicity assay}

The cytotoxic effect of compound 3K was examined using MTT (1 mg/ml, Sigma-Aldrich) assay. The cells were seeded onto a 96-well plate at a density of $3 \times 10^{3}$ cells/well for $24 \mathrm{~h}$, followed by treatment with varying drug concentrations $(1-15 \mu \mathrm{M})$ for 24 and $48 \mathrm{~h}$. Next, $100 \mu \mathrm{l}$ of MTT reagent was added at the endpoints, following which the cells were further incubated at $37^{\circ} \mathrm{C}$ in the dark for $3 \mathrm{~h}$. The absorbance of each well was measured at $540 \mathrm{~nm}$ using a VERSA Max Microplate Reader (Molecular Devices Corp., CA, and USA). The $\mathrm{IC}_{50}$ value was calculated using the Sigma Plot 10.0 software from sigmoidal dose-response relationships.

\section{Clonogenic assay}

SK-OV-3 cells were grown in 6-well plates at a density of $1 \times 10^{3}$ cells/well for $24 \mathrm{~h}$, and the cells were subsequently treated with compound $3 \mathrm{~K}(1,2.5$, or 5 $\mu \mathrm{M})$ for 10 days. The cells were stained with $0.05 \%$ crystal violet for $3 \mathrm{~h}$ following the fixing of the colonies with $4 \%$ paraformaldehyde. Relative colony area was analyzed using an image analyzer.

\section{Western blot analysis}

SK-OV-3 cells were harvested after $24 \mathrm{~h}$ of treatment with compound $3 \mathrm{~K}(1,2.5$, or $5 \mu \mathrm{M})$. The cells were lysed and total protein was extracted with the PRO-PREPTM extraction solution. Equal amounts of protein were separated on sodium dodecyl sulfate polyacrylamide gels and transferred onto a polyvinylidene difluoride (PVDF) membrane. The PVDF membranes were incubated with the primary antibodies overnight at $4{ }^{\circ} \mathrm{C}$, washed with tris-buffered saline, followed by treatment with HRP-conjugated anti-mouse or anti-rabbit antibodies. The protein bands were visualized using a ChemiDoc imaging system (Bio-Rad, Hercules, CA, USA). The intensities of the bands were calculated using an image analyzer.

\section{AnnexinV-FITC binding assay}

The Annexin V-FITC analysis was performed using the Annexin V-FITC staining kit I (BD Biosciences, San Diego, CA, USA). SK-OV-3 cells were treated with compound $3 \mathrm{~K}(1,2.5$, or $5 \mu \mathrm{M})$ for $24 \mathrm{~h}$. After the cells were harvested, $5 \mu$ l of Annexin V-FITC and propidium iodide (PI) each in $100 \mu \mathrm{l}$ of binding buffer were added, followed by incubation for $15 \mathrm{~min}$ in the dark. After the addition of $400 \mu \mathrm{l}$ of $1 \times$ binding buffer, the cells were analyzed using flow cytometry (Guava EasyCyte flow cytometer; Millipore, MA, USA).

\section{Cell cycle assay}

The cells were cultured with compound $3 \mathrm{~K}(1$, 2.5 , or $5 \mu \mathrm{M}$ ) or $0.1 \%$ DMSO (control), and the attached cells were harvested after $24 \mathrm{~h}$ and fixed with $70 \%$ cold $\mathrm{EtOH}$ at $4^{\circ} \mathrm{C}$ overnight. The cells were re-suspended in $0.5 \mathrm{ml}$ phosphate buffered saline (PBS) containing $5 \mu \mathrm{l}$ of staining solution ( $1 \mathrm{mg}$ of PI in $1 \mathrm{ml}$ of PBS) and RNase A (10 mg/ml), followed by incubation in the dark for $30 \mathrm{~min}$ at $37^{\circ} \mathrm{C}$. Next, the cells were analyzed using flow cytometry (Guava ${ }^{\circledR}$ EasyCyte flow cytometer).

Table 1. Clinicopathological characteristics of the experimental microarray samples (143 ovarian adenocarcinoma tissue and 18 normal ovary tissue samples)

\begin{tabular}{|c|c|c|c|c|c|c|c|}
\hline \multirow[t]{2}{*}{ Variable } & \multirow[t]{2}{*}{ Patients (Female) } & \multicolumn{3}{|c|}{ Tumor stage, n (\%) } & \multicolumn{3}{|c|}{ Histological grade, n (\%) } \\
\hline & & I & II & III \& IV & 1 & 2 & 3 \\
\hline Cancer (\%) & $143(100 \%)$ & $62(43.4 \%)$ & $33(23.1 \%)$ & $48(33.6 \%)$ & $32(24.6 \%)$ & $40(30.8 \%)$ & $58(44.6 \%)$ \\
\hline Normal (\%) & $18(100 \%)$ & - & - & - & - & - & - \\
\hline
\end{tabular}




\section{Acridine orange fluorescent staining}

SK-OV-3 cells were cultured in confocal dishes, and after $24 \mathrm{~h}$, they were treated with compound $3 \mathrm{~K}$ $(1,2.5$, or $5 \mu \mathrm{M})$ for an additional $24 \mathrm{~h}$. The cells were stained with acridine orange $(1 \mu \mathrm{g} / \mathrm{ml})$ for $15 \mathrm{~min}$ and washed five times with PBS to remove the medium containing the dye. The cells were examined using a K1-fluo microscope (Nanoscope Systems, Daejeon, Korea) at 400× magnification.

\section{DAPI nuclear Staining}

The nuclear morphology and presence of apoptotic bodies were visualized using DAPI nuclear staining. SK-OV-3 cells growing in a confocal dish were treated with compound $3 \mathrm{~K}(1,2.5$, or $5 \mu \mathrm{M})$ for $24 \mathrm{~h}$, and then the cells were fixed with acetone for 20 min. Next, the cells were washed five times with PBS, treated with $(0.1 \mu \mathrm{g} / \mathrm{ml}$ DAPI in PBS for $5 \mathrm{~min}$, and then re-washed with PBS. The nuclear morphology and apoptotic bodies in the cells were analyzed using fluorescence microscopy. Apoptotic cells were identified based on the characteristic changes including the presence of fragmented, condensed, and degraded nuclei.

\section{Immunocytochemistry for PKM2}

SK-OV-3 cells were cultivated in confocal dishes and then treated with compound $3 \mathrm{~K}(1,2.5$, or $5 \mu \mathrm{M})$. Next, the cells were fixed in acetone for $20 \mathrm{~min}$, followed by removal with ice-cold PBS. Next, the cells were treated with 10\% normal goat serum in PBS for 30 min before incubation with PKM2 antibody (1:500) at $4{ }^{\circ} \mathrm{C}$ overnight. The cells were washed five times with PBS and incubated with rhodamine conjugated secondary antibody for $30 \mathrm{~min}$. Next, the cells were washed three times with PBS, stained with $(0.1 \mu \mathrm{g} / \mathrm{ml}$ DAPI in PBS for $5 \mathrm{~min}$, and washed again with PBS. Finally, the cells were examined under a K1-fluo microscope (Nanoscope Systems, Daejeon, Korea) at 400× magnification. Mean fluorescence intensity was analyzed using an image analyzer.

\section{Seahorse XF96 analysis of the extracellular acidification rate (ECAR)}

A Seahorse XF96 analyzer (Agilent, Santa Clara, USA) was used to monitor the ECAR continuously. Two days prior to performing the experiment, the cells were grown in a XF96 well plate at a density of 2 $\times 10^{3}$ cells/well at $37^{\circ} \mathrm{C}$ in $5 \% \mathrm{CO}_{2}$. One day prior to the experiment, $200 \mu \mathrm{l}$ of XF calibration buffer was added to each well of the XF cartridge, followed by incubation in an atmosphere of $0 \% \mathrm{CO}_{2}$ at $37{ }^{\circ} \mathrm{C}$ overnight. Thirty minutes prior to the experiment, the cells were washed with PBS and $200 \mu$ l of XF assay medium was added to each well, followed by incubation for $30 \mathrm{~min}$ in an atmosphere of $0 \% \mathrm{CO}_{2}$ at $37^{\circ} \mathrm{C}$. For the XF glycolysis stress analysis, $300 \mathrm{mg} / \mathrm{L}$ glutamine was added to the $\mathrm{XF}$ assay medium. After equilibration time, different compounds $(10 \times$ final concentration) were added to the injection ports. The substrate consisted of $2 \mu \mathrm{M}$ oligomycin, $10 \mathrm{mM}$ glucose, and $50 \mathrm{mM}$ 2-deoxyglucose. All the reagents for ECAR were purchased from Seahorse Bioscience.

\section{Quantification of lactate level in medium}

Liquid chromatography (LC) system included a UV/Vis-151 detector (Gilson), an autosampler (Gilson-234), and a LC-321/322/350 pump (Gilson, France). Detection and quantification were performed using a Synergi Hydro-RP C18 column $(250 \times 4.6 \mathrm{~mm}$, $4 \mu \mathrm{m}, 80 \AA$; Phenomenex, USA). The flow rate was maintained at $0.8 \mathrm{ml} / \mathrm{min}$ for lactate. Isocratic mobile phases included $0.1 \%$ phosphoric acid in water for lactate. After extraction, the samples were transferred to a sample tube with acetonitrile containing thiamine (internal standard) and mixed thoroughly. The samples were centrifuged for $5 \mathrm{~min}$ at $1503 \times \mathrm{g}$. The supernatants were analyzed by performing HPLC (LC-321/322/350 pump) at $210 \mathrm{~nm}$ for lactate.

\section{IncuCyte ZOOM analysis}

The effect of compound $3 \mathrm{~K}$ on scratch-wound migration and cell confluency of ovarian cancer cells was examined using the IncuCyte $\mathrm{ZOOM}^{\mathrm{TM}}$ system (Essen Bioscience, MI, USA) that quantitatively detects live cells in real time. The cells were seeded and treated with compound $3 \mathrm{~K}(1,2.5$, or $5 \mu \mathrm{M})$ for 48 $\mathrm{h}$. To monitor cell confluency, the cells were plated in 96-well plates at a density of $3 \times 10^{3}$ cells/well and incubated for $24 \mathrm{~h}$. The cells were treated with compound $3 \mathrm{~K}(1,2.5$, or $5 \mu \mathrm{M})$ and images were acquired every $6 \mathrm{~h}$. All the photographs were analyzed, and confluency was calculated using the IncuCyte $\mathrm{ZOOM}^{\mathrm{TM}}$ software. The cells were seeded onto 96-well plates (IncuCyte Image-Lock Plates, Essen Bioscience) at a density of $1 \times 10^{4}$ cells/well, $5 \%$ $\mathrm{CO}_{2}$, and $37{ }^{\circ} \mathrm{C}$ for performing the wound-healing assay. At $100 \%$ confluency, a WoundMaker (Essen Bioscience) was used to create a scratch-wound, and the cells were treated with compound $3 \mathrm{~K}(1,2.5$, or 5 $\mu \mathrm{M})$. The images were acquired every $6 \mathrm{~h}$, and the relative wound healing density was calculated using the IncuCyte software. Each experiment was performed in at least six wells.

\section{In vivo tumor xenograft study}

Female BALB/c nude mice (4-week-old) were obtained from Central Lab Animal Inc. (Hamamatsu, Japan). They were housed in controlled temperature $\left(22 \pm 2{ }^{\circ} \mathrm{C}\right)$ conditions and a $12 \mathrm{~h}$ environmental light/dark cycle. The experimental procedure was 
approved by the Sungkyunkwan University Institutional Animal Care and Use Committee (SKKUIACUC2019 -12-18-1). For the establishment of tumors, SK-OV-3 cells $\left(1 \times 10^{7}\right)$ suspended in serum-free RPMI containing 50\% Matrigel were injected subcutaneously in the right flank of the mice. The tumor volumes $(\mathrm{V})$ were calculated every third day using a caliper and the following standard formula: $\mathrm{V}\left(\mathrm{mm}^{3}\right)=0.52\left(\mathrm{ab}^{2}\right)(\mathrm{a}=$ length, $\mathrm{b}=$ width $)$ [19]. Once the tumor reached $200 \mathrm{~cm}^{3}$, the mice were randomly divided into two groups ( $\mathrm{n}=5$ per group). According to previous studies [20, 21], compound 3K ( $5 \mathrm{mg} / \mathrm{kg}$ body weight) dissolved in $1 \mathrm{ml}$ of solvent (DMSO:corn oil, 1:9) was administered orally every 2 days for 31 days. The control group was treated with an equal volume of the vehicle. The weights of the tumors were measured in each group. IHC analysis was conducted in the two groups, and the number of Ki-67 positive cells was analyzed using an image analyzer.

\section{Statistical analysis}

All the data are expressed as the mean \pm standard deviation (SD) of at least three independent experiments. The analysis of statistical significance was conducted using one-way analysis of variance (ANOVA) followed by Bonferroni's post-hoc comparisons test. Our analysis was conducted using Graph Pad Prism Software version 5.0 (GraphPad Software, CA, USA). A p value $<0.05$ indicated statistical significance.

\section{Results}

\section{PKM2 overexpression is correlated with severity of ovarian cancer}

The expression of PKM2 was examined in 143

A
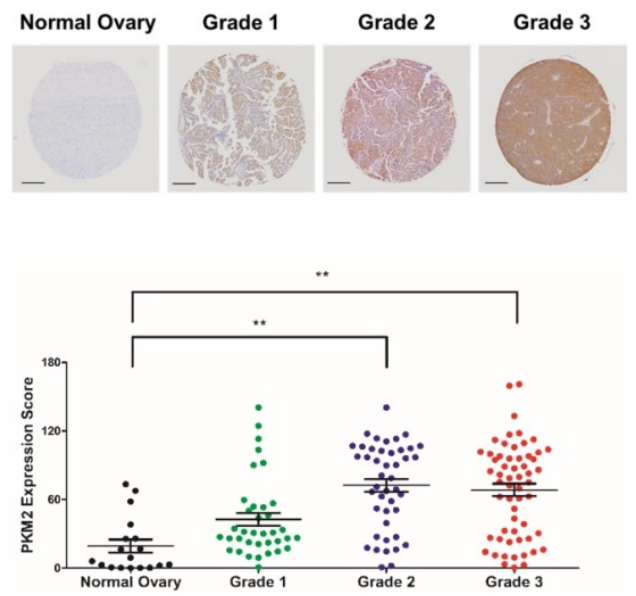

human ovarian adenocarcinoma tissue samples obtained from patients aged 22-75 years and compared with that in 18 normal ovarian tissue samples obtained from normal subjects aged 14-41 years. PKM2 expression had a positive correlation with the grade and stage of ovarian adenocarcinoma tissues (Figures 1A, B). These results indicate that a high expression of PKM2 is associated with poor survival of ovarian cancer patients.

\section{Cytotoxicity of compound $3 K$ in SK-OV-3 cells}

A previous study reported a high expression of PKM2 in various cancer cells [22]. We compared the basal expression of PKM2 and PKM1 in various ovarian cancer cell lines using western blot analysis and found that the PKM2 protein level was upregulated in the ovarian adenocarcinoma cell line, SK-OV-3, compared with the other ovarian cancer cell lines (Figure 2A). The chemical structure of compound $3 \mathrm{~K}$ is presented in Figure 2B. The cytotoxicity of various concentrations of compound $3 \mathrm{~K}$ in the SK-OV-3 cell line was evaluated using 3-(4,5-dimethylthiazol-2-yl)-2,5-diphenyl-tetrazolium bromide (MTT) assay. The $\mathrm{IC}_{50}$ value of compound $3 \mathrm{~K}$ in the SK-OV-3 cells was assessed from a dose-response relationship curve. The cytotoxicity of compound 3K in the SK-OV-3 cells is shown in Figure $2 \mathrm{C}$. Compound $3 \mathrm{~K}$ exhibited potent cytotoxicity against SK-OV-3 cells in a time- and concentration-dependent manner, with $\mathrm{IC}_{50}$ values of 7.82 and $5.82 \mu \mathrm{M}$ after 24 and $48 \mathrm{~h}$ of treatment, respectively. Noticeable morphological changes included expansion induced by compound $3 \mathrm{~K}$ in the cells after $24 \mathrm{~h}$ of treatment (Figure 2D).

B

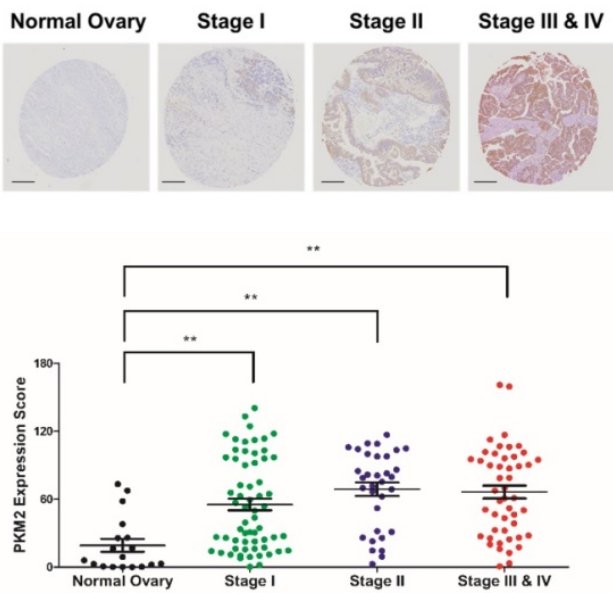

Figure 1. Expression pattern of PKM2 in tissue microarray. (A, B) Ovarian adenocarcinoma and normal ovarian tissue samples were analyzed for changes in PKM2 expression using immunohistochemistry. PKM2 immunostaining scores in the ovarian cancer and normal ovarian tissue samples associated with the four different tumor grades and stages. Scale bar, $200 \mu \mathrm{m}$. The values represent the mean \pm SD. ${ }^{*} \mathrm{p}<0.05$ and $*^{*} \mathrm{p}<0.01$. 
A

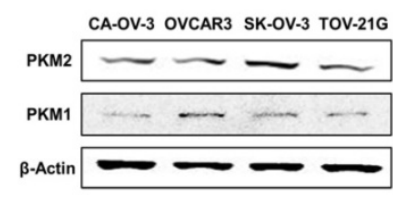

C

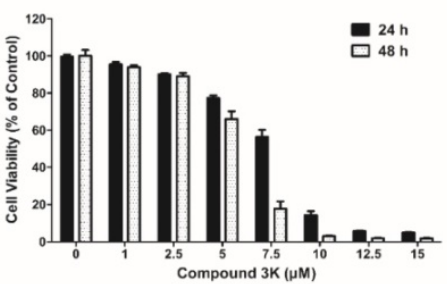

B

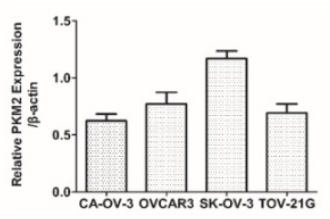

D

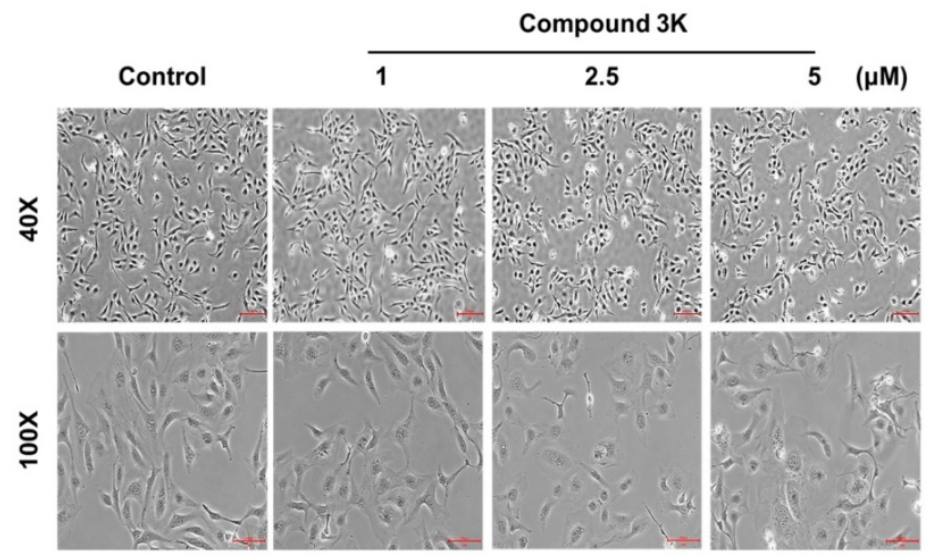

Figure 2. Protein expression level of PKM2 and PKM1 in ovarian adenocarcinoma cell lines and the effect of compound $3 \mathrm{~K}$ on cell viability and cell morphology of SK-OV-3 cells. (A) Comparison of PKM2 and PKM1 expression level in four ovarian adenocarcinoma cell lines. $\beta$-actin served as a positive loading control. The band intensity of PKM2 was calculated and expressed as a ratio of $\beta$-actin expression in the graph. (B) The chemical structure of compound $3 \mathrm{~K}$. (C) Cells were treated with compound $3 \mathrm{~K}$ at various concentrations (1-15 $\mu \mathrm{M})$ for 24 and $48 \mathrm{~h}$. Cell cytotoxicity was assessed using an 3-(4, 5-dimethylthiazol-2-yl)-2, 5-diphenyltetrazolium bromide (MTT) assay. (D) Light microscopic images show morphological changes in the cells after compound $3 \mathrm{~K}(1,2.5$, or $5 \mu \mathrm{M})$ treatment for $24 \mathrm{~h}$. Scale bar, $200 \mu \mathrm{m}(40 \times)$, 100 $\mu \mathrm{m}(100 \times)$. The values represent the mean $\pm \mathrm{SD}$. ${ }^{*} \mathrm{p}<0.05$ and $* * \mathrm{p}<0.01$.

\section{Compound $3 K$ affects the expression of PKM2 and not that of PKMI in SK-OV-3 cells}

Results of western blot analysis of whole-cell lysates showed a robust reduction in PKM2 protein expression in SK-OV-3 cells treated with compound 3K without any change in PKM1 protein expression (Figures 3A). Consistently, immunofluorescence analysis showed marked decrease in PKM2 protein levels in compound 3K-treated SK-OV-3 cells (Figure 3B). To determine the most effective treatment timepoint that completely inhibits PKM2 protein expression, cells were treated with $5 \mu \mathrm{M}$ compound $3 \mathrm{~K}$ for various timepoints ranging from 0 to $24 \mathrm{~h}$. The maximum decrease in PKM2 expression was observed at $24 \mathrm{~h}$ (Figure 3C).

\section{Compound $3 \mathrm{~K}$ inhibits proliferation and colony formation and regulates the cell cycle in SK-OV-3 cells}

To evaluate the effect of compound $3 \mathrm{~K}$ on the proliferation of an ovarian adenocarcinoma cell line, SK-OV-3 cells were treated with the indicated concentration $(1,2.5$, or $5 \mu \mathrm{M})$ for $48 \mathrm{~h}$. Cell confluency was calculated with the IncuCyte software, which quantitatively detects live cells every 6 h. Compound $3 \mathrm{~K}$ noticeably reduced the proliferation ability of SK-OV-3 cells in a concentration-dependent manner with the maximum decrease in proliferation ability observed at $48 \mathrm{~h}$ (Figure 4A). To demonstrate the anticancer effects of compound $3 \mathrm{~K}$, a clonogenic assay was conducted. As shown in Figure 4B, colony formation of SK-OV-3 cells was markedly inhibited, following treatment with compound 3K. To identify the effect of compound $3 \mathrm{~K}$ on the regulation of cell cycle, SK-OV-3 cells were treated with compound $3 \mathrm{~K}(1,2.5$, or $5 \mu \mathrm{M})$ for $24 \mathrm{~h}$; next, their DNA content was analyzed using flow cytometry. As shown in Figure 4C, compound $3 \mathrm{~K}$ induced G2/M arrest of SK-OV-3 cells and simultaneously decreased the portion of cells in G1 phase in a concentration-dependent manner. The relative distribution of cells in the different phases of the cell cycle is displayed in Figure 4D. To identify the effect of compound $3 \mathrm{~K}$ on the expression level of cell cycle-related proteins, western blotting was performed (Figure 4E). The expression levels of Cdc2 and cyclin B1 did not change significantly, whereas the expression level of $\mathrm{p}-\mathrm{Cdc} 2$ increased in the compound 3K-treated SK-OV-3 cells. These results suggest that compound $3 \mathrm{~K}$ inhibited the proliferation, colony formation, and cell cycle progression of SK-OV-3 cells. 
A

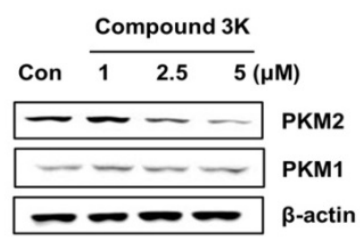

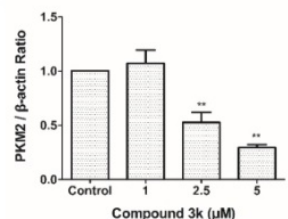

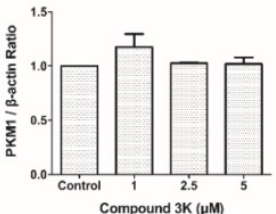

C

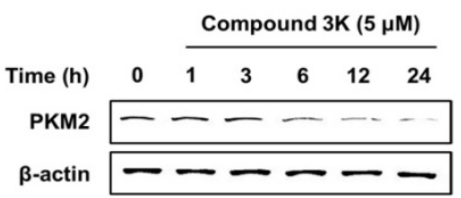

B
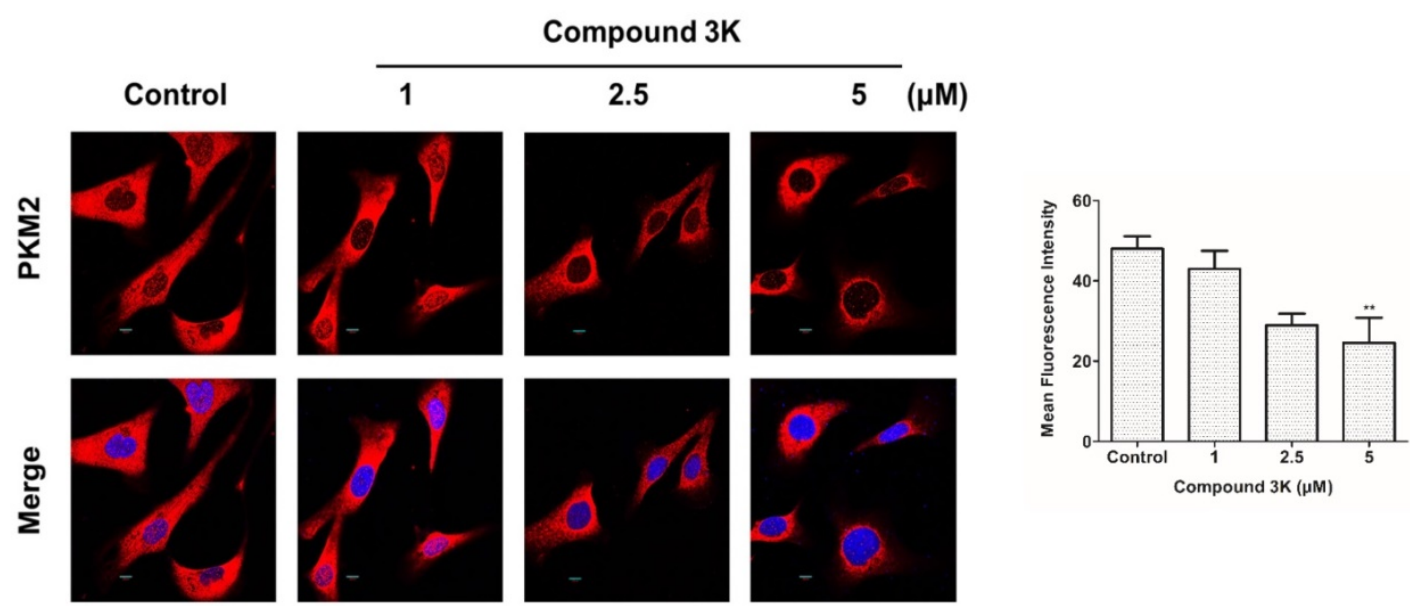

Figure 3. Effect of compound $3 \mathrm{~K}$ on PKM2 and PKM1 expression. (A) Effect of compound $3 \mathrm{~K}$ on the protein expression levels of PKM2 and PKM1. Cells were treated with compound $3 \mathrm{~K}(1,2.5$, or $5 \mu \mathrm{M})$ for $24 \mathrm{~h}$ and expression level of the proteins was determined using western blotting. The band intensity of PKM2 and PKM1 were calculated and expressed as a ratio of $\beta$-actin expression in the graph. (B) Immunofluorescence of PKM2 labeled with an antibody to total PKM2 (Red). DAPI (blue) was used as a nuclear staining. (Magnification $\times 600)$. The mean fluorescence intensity of PKM2 was calculated and expressed in the graph. (C) Cells were treated with compound $3 K(5 \mu M)$ for different time points, and then western blotting was conducted. The values represent the mean \pm SD. ${ }^{*} p<0.05$ and ${ }^{* *} p<0.01$.

\section{Compound $3 K$ affects SK-OV-3 cell metastasis}

Ovarian cancers are highly metastatic in the advanced stages [23]. We investigated the effect of compound $3 \mathrm{~K}$ on the migration of SK-OV-3 using a scratch-wound assay. The cells treated with compound $3 \mathrm{~K}$ showed relatively lower wound healing ability than those in the control group (Figure 5A). The control and compound 3K-treated cells showed significant differences in relative wound healing at $72 \mathrm{~h}$ post-scratch (Figure $5 \mathrm{~B}$ ). These changes increased time-dependently. Additionally, the results of western blot analysis showed that compound 3K increased the protein expression of TIMP-2 and decreased that of matrix metalloproteinases protein (MMP) in a dose-dependent manner (Figures 5C, D). Thus, compound $3 \mathrm{~K}$ inhibited the metastasis of SK-OV-3 cells.

\section{Compound $3 K$ induces apoptotic and autophagic cell death in SK-OV-3 cells}

PKM2 regulation is associated with apoptosis and autophagy [17]. Annexin V/PI assay, western blot analysis, and 4'-6-diamidino-2-phenylindole (DAPI) staining were performed to assess apoptotic cell death following compound 3K treatment. After 24 $\mathrm{h}$, the proportion of the late-stage apoptotic cell population increased in the compound 3K-treated group, when compared with that in the control group (Figure 6A). Next, we assessed the expression level of apoptotic proteins using western blotting. Compound $3 \mathrm{~K}$ increased the expression of Bax and decreased the expression of Bcl-2 and caspase 3 in SK-OV-3 cells (Figures 6B). DAPI nuclear staining was performed to examine the apoptotic cells using confocal microscopy. The compound 3K-treated group showed the presence of apoptotic nuclei (fragmented or condensed chromatin) (Figure 6C). To determine if autophagy was induced by compound $3 \mathrm{~K}$, acridine orange and western blot analysis were conducted. Autophagy activation was clearly observed by acridine orange staining of cells mediated by the accumulation of the lysotropic dye in acidic organelles in a pH-dependent manner [24]. Compound 3K-treated cells showed autophagic vacuoles with higher red fluorescence intensity at $24 \mathrm{~h}$ (Figure 6D). The change of the soluble form of LC3-I to LC3-II, the autophagic vacuole-related form, is a major index of autophagosome formation. Compound 3K markedly increased the expression level of LC3-II. Moreover, the results showed a similar tendency in the expression of other relevant proteins including p62, Atg5-Atg12 complex, and Beclin-1 in the compound 3K-treated groups (Figure 6E). 
A

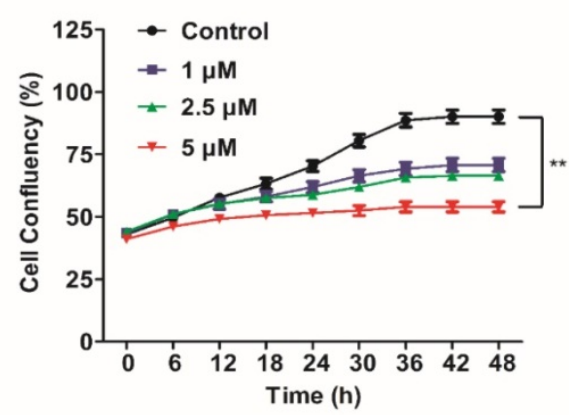

B

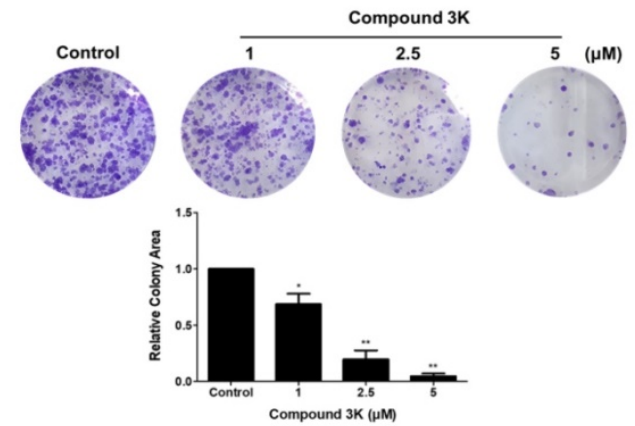

C

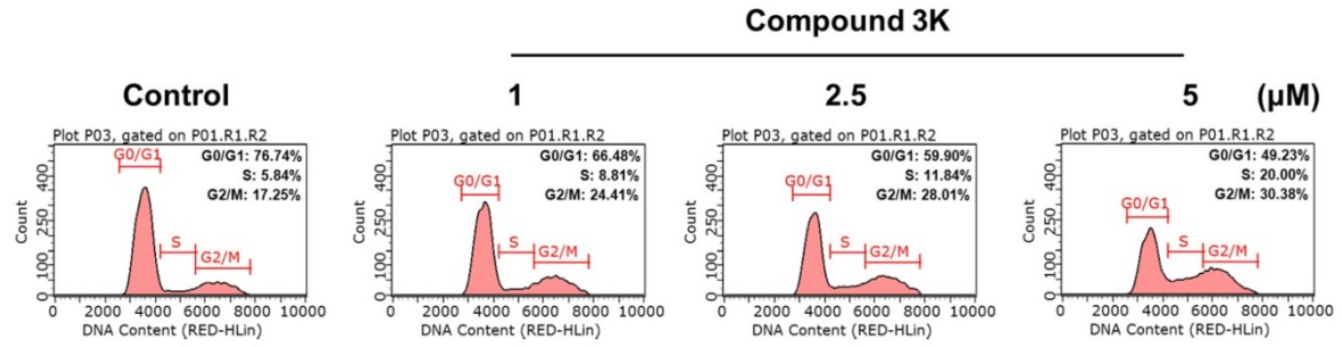

D

E
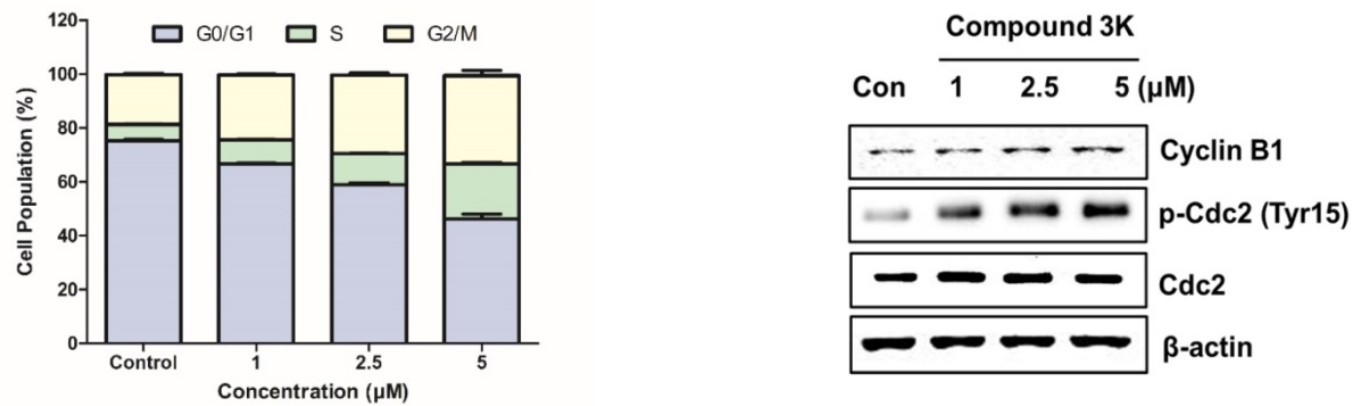

Figure 4. Compound $3 \mathrm{~K}$ reduced colony formation and cell proliferation and induced the cell cycle arrest in SK-OV-3 cells. (A) Effect of compound $3 \mathrm{~K}$ ( $1,2.5$, or $5 \mu \mathrm{M}$ ) on proliferation of SK-OV-3 cells following treatment for $48 \mathrm{~h}$. Cell proliferation was checked with an IncuCyte software every $6 \mathrm{~h}$. (B) Representative photographs and quantitative analysis of colony formation assay of SK-OV-3 cells treated with indicated compound $3 \mathrm{~K}$ concentrations in 6 -well plates. Colony areas were measured using image analyzer. (C) SK-OV-3 cells were treated with compound $3 \mathrm{~K}(1,2.5$, or $5 \mu \mathrm{M})$ for $24 \mathrm{~h}$. After treatment, the cells were stained with propidium iodide (PI) and analyzed using flow cytometry. (D) Bar graph indicating the different phases of cell cycle distributions of SK-OV-3 cells treated with $0.1 \%$ DMSO control or compound $3 \mathrm{~K}$. (E) Effect of compound $3 \mathrm{~K}$ on the expression of cell cycle-related proteins. SK-OV-3 cells were treated for $24 \mathrm{~h}$ with compound $3 \mathrm{~K}(1,2.5$, or $5 \mu \mathrm{M})$. The expression of cyclin B1, p-Cdc2, and Cdc2 were analyzed using western blot analysis. The values represent the mean \pm SD. ${ }^{*} \mathrm{p}<0.05$ and $*^{*} \mathrm{p}<0.01$.

\section{PKM2 regulates ovarian cancer cell growth through the AKT/AMPK/mTOR pathway}

To determine the molecular mechanism through which PKM2 regulates the proliferation and growth of SK-OV-3 cells, we measured the expression levels of proteins associated with the PKM2-targeting molecular pathways in the compound 3K-treated SK-OV-3 cells using western blot analysis. Our results demonstrated that the PKM2/AKT/mTOR pathway was markedly inhibited in compound 3K-treated SK-OV-3 cells (Figures 7A, B). In addition, compound $3 \mathrm{~K}$ significantly downregulated the expression of p-Akt, which led to the inhibition of mTOR phosphorylation and promotion of autophagy. The expression of Akt and mTOR was unchanged in the control group. Moreover, the inhibition of PKM2 increased the expression of p-AMPK, which in turn decreased mTOR phosphorylation. The induction of AMPK suppressed mTOR activity and negatively regulated protein synthesis; hence, we assessed the expression level of p-p70S6K, a main target of mTOR. Our data showed that p-p70S6K was inhibited in response to increased $\mathrm{p}$-AMPK following PKM2 inhibition. These results indicate that the inhibition of PKM2 by compound $3 \mathrm{~K}$ treatment resulted in a decrease in AKT phosphorylation and an increase in AMPK phosphorylation, causing decreased phosphorylation of mTOR and p70S6K. 
A

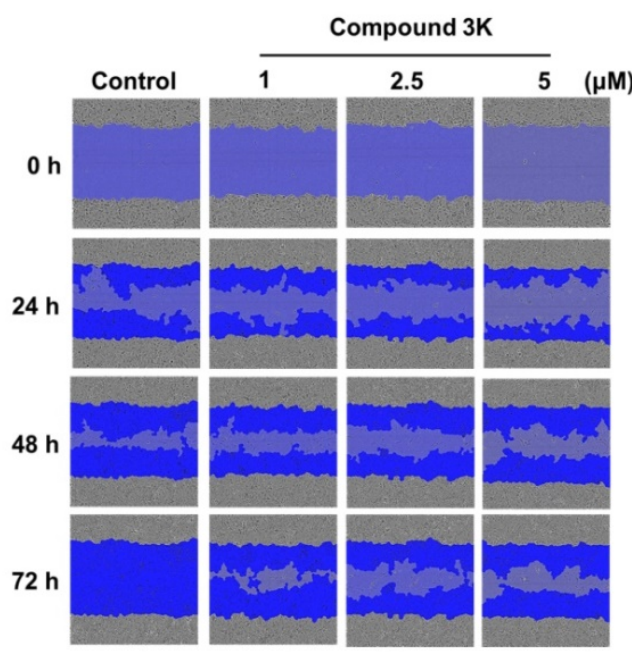

C

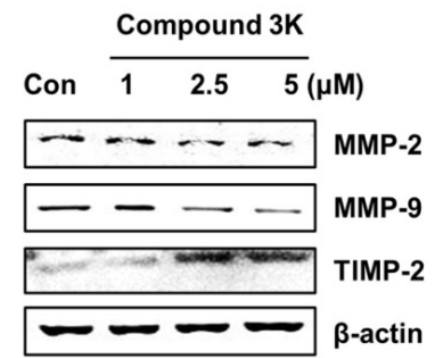

B

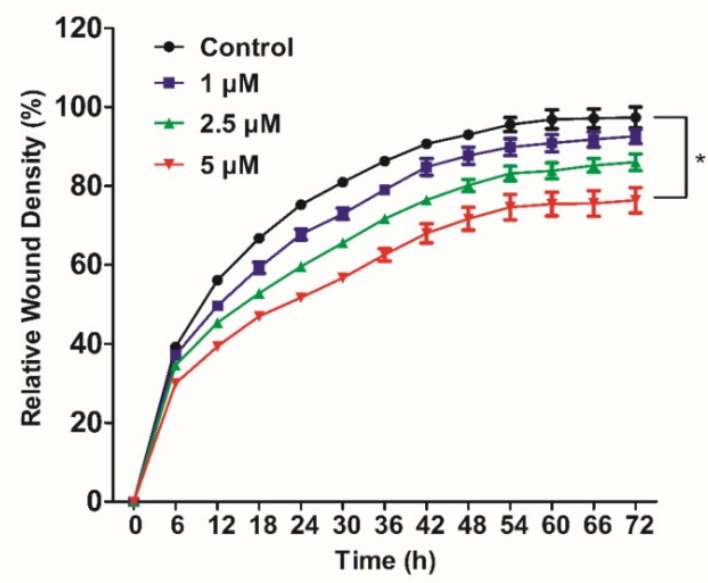

D
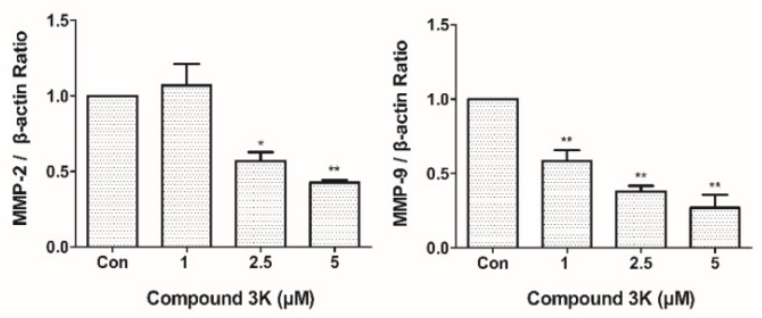

Figure 5. Compound $3 \mathrm{~K}$ inhibits metastasis of SK-OV-3 cells. (A) The inhibitory effect of compound $3 \mathrm{~K}$ on cell migration was evaluated using IncuCyte software. The blue area represents the wounded area. (B) The change in relative wound areas is shown. (C) Western blot analysis showing the protein levels of metastatic markers (MMP-2, MMP- 9 , and TIMP-2) in SK-OV-3 treated with compound 3K $(1,2.5$, or $5 \mu M)$. (D) Quantitative data of protein levels of the metastatic marker. The values represent the mean \pm SD. *p $<0.05$ and $*^{* *} \mathrm{p}<0.01$.

\section{Compound $3 \mathrm{~K}$ altered the glucose metabolism in SK-OV-3 cells}

To assess cellular bioenergetics in SK-OV-3, the Seahorse analyzer was used to identify changes in glycolytic function in the cells. The Seahorse analyzer measures ECAR, an indicator of glycolytic function, in cells during lactate production. As shown in Figure $8 \mathrm{~A}$, compound $3 \mathrm{~K}$ decreased ECAR in a concentration-dependent manner. Glycolytic function can be estimated by evaluating various parameters such as glycolysis, glycolytic capacity, non-glycolytic acidification, and glycolytic reserve. There was a reduced glycolytic function in the compound 3K-treated groups compared with the control group (Figure 8B), indicating that compound 3K significantly induced glycolytic dysfunction. To identify the effect of compound $3 \mathrm{~K}$ on the generation of cellular metabolites, we quantitatively analyzed lactate level in the culture media of the ovarian cancer cells using high performance liquid chromatography (HPLC). Compound 3K inhibited lactate production in a dose-dependent manner (Figure 8C). Furthermore, western blot analysis demonstrated that compound $3 \mathrm{~K}$ reduced the expression levels of glucose transporter 1 (GLUT1), lactate dehydrogenase A (LDHA), and monocarboxylate transporter 4 (MCT4) considerably (Figure 8D), which might have caused decreased rates of glucose uptake, pyruvate conversion, and lactate efflux, respectively.

\section{Compound $3 K$ inhibits cell growth in a SK-OV-3 tumor xenograft model}

To identify the effect of compound $3 \mathrm{~K}$ in a tumor xenograft model, SK-OV-3 cells $\left(1 \times 10^{7}\right)$ were injected subcutaneously into BALB/c nude mice. The treatment began when the tumors were $200 \mathrm{~cm}^{3}$ and the mice were orally administered $5 \mathrm{mg} / \mathrm{kg}$ compound $3 \mathrm{~K}$ for 31 days. Compound $3 \mathrm{~K}$ treatment markedly decreased the tumor volume (Figures 9A, B) and tumor weight (Figure 9C), compared with the control group. No significant weight reduction was detected in the mouse treated with compound $3 \mathrm{~K}$ (Figure 9D), suggesting that compound 3K did not cause any major organ toxicity. The proportion of Ki-67-positive cells is an important index of cell proliferation, and immunohistochemistry (IHC) analysis of the tumor tissue showed a high number of 
A

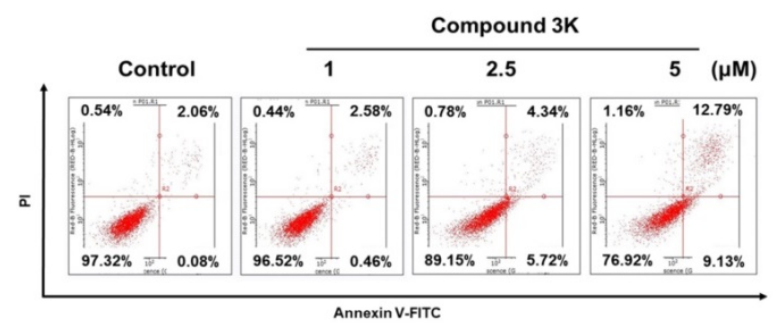

C
Compound 3k
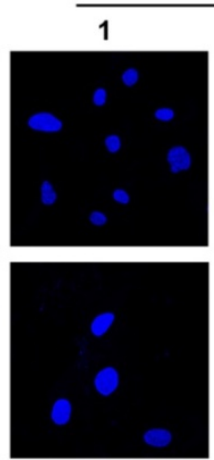
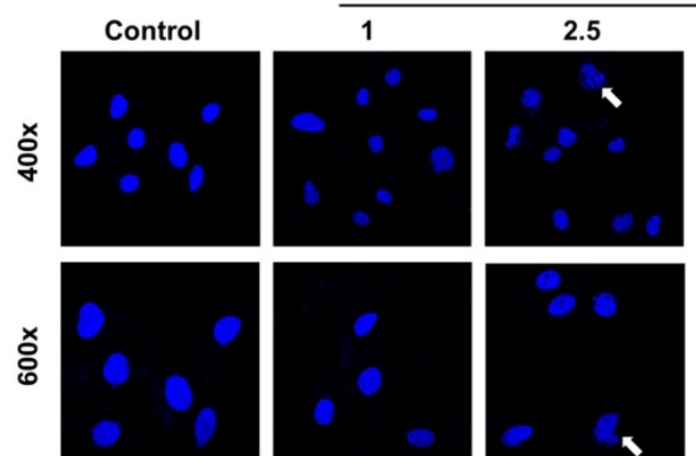

D
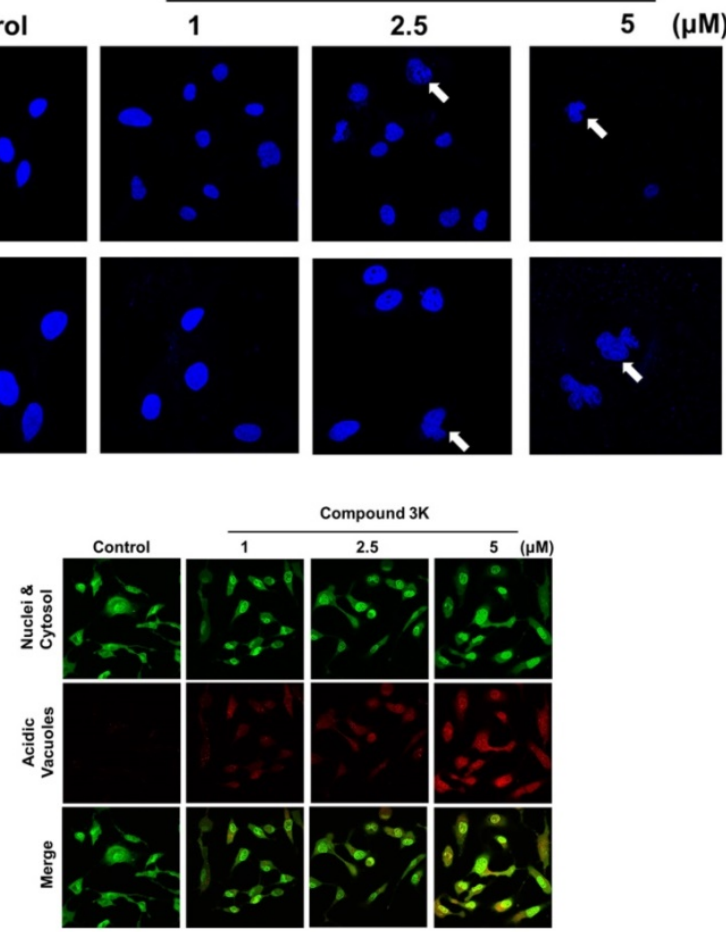

B
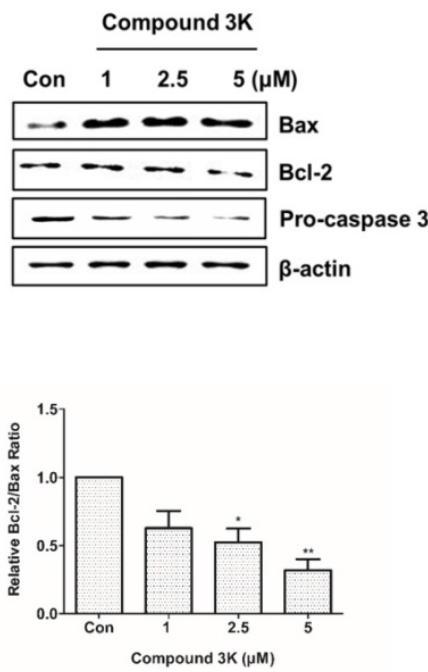

E

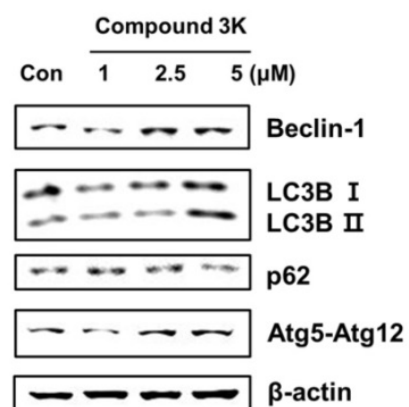

Figure 6. Apoptosis and autophagy induced by compound $3 \mathrm{~K}$ in SK-OV-3 cells. (A) Cells were treated with vehicle control or compound $3 \mathrm{~K}$ (1, 2.5 , or $5 \mu \mathrm{M})$ for 24 h. After treatment, the cells were stained with PI and FITC-conjugated Annexin V for flow cytometric analysis. (B) Cells were treated with vehicle control or compound $3 \mathrm{~K}$ (1, 2.5 , or $5 \mu \mathrm{M})$ for $24 \mathrm{~h}$ and the expression level of pro-apoptotic proteins was analyzed by western blotting. The ratio of Bcl-2/Bax was calculated and expressed as a graph. (C) Effect of compound $3 \mathrm{~K}$ on nuclear morphological changes determined by DAPI nuclear staining. Photographs were obtained using a confocal K1-fluo microscope (Nanoscope Systems, Daejeon, Korea) (Magnification $\times 400$ and $\times 600$ ). (D) Representative micrographs of acridine orange staining of SK-OV-3 cells following treatment with compound $3 \mathrm{~K}$ (Magnification $\times 400$ ). (E) Western blot analysis shows the protein levels of autophagy markers in SK-OV-3 treated with compound $3 \mathrm{~K}$ (1, 2.5 , or $5 \mu \mathrm{M})$ for $24 \mathrm{~h}$. The values represent the mean \pm SD. $*_{p}<0.05$ and $* * p<0.01$.

Ki-67-positive cells in the control group. However, the intensity of Ki-67 staining decreased in the tumor tissues from the compound 3K-treated mice (Figure 9E). All our results indicate that compound $3 \mathrm{~K}$ inhibited SK-OV-3 cell growth in vivo.

\section{Discussion}

Cancer cells rely heavily on PKM2 for their energy needs; it is an essential enzyme for the final rate-limiting step of the glycolytic pathway, and thus, it plays a critical role in cancer cell metabolism and growth [4]. Clinically, PKM2 overexpression is associated with the tumorigenesis of various cancers and poor outcome for cancer patients [11, 25-27]. In the current study, we observed a stronger PKM2 immunostaining in grades 2 and 3 and stages III and IV ovarian adenocarcinoma tissue samples, compared with that in normal ovarian samples, thus confirming that increased PKM2 expression is associated with ovarian tumorigenesis. The prognosis for patients with advanced ovarian cancer remains poor because of the ineffectiveness of chemotherapy or radiation therapy in ovarian cancers [2]. Given that PKM2 overexpression is highly associated with advanced ovarian cancers, the development of novel anticancer drugs or therapeutics that can target PKM2 could be an important strategy to improve the survival rate of patients with PKM2-overexpressing ovarian cancer. To date, several PKM2 inhibitors, including shikonin, metformin, vitamin $\mathrm{K}$, and temozolomide, have been identified [9]. Our study focused on the effects of compound $3 \mathrm{~K}$, a specific PKM2 inhibitor, in ovarian cancer cells, and we mechanistically demonstrated that the effects of compound $3 \mathrm{~K}$ were mediated by the targeting of metabolism for therapeutic benefit. 
A

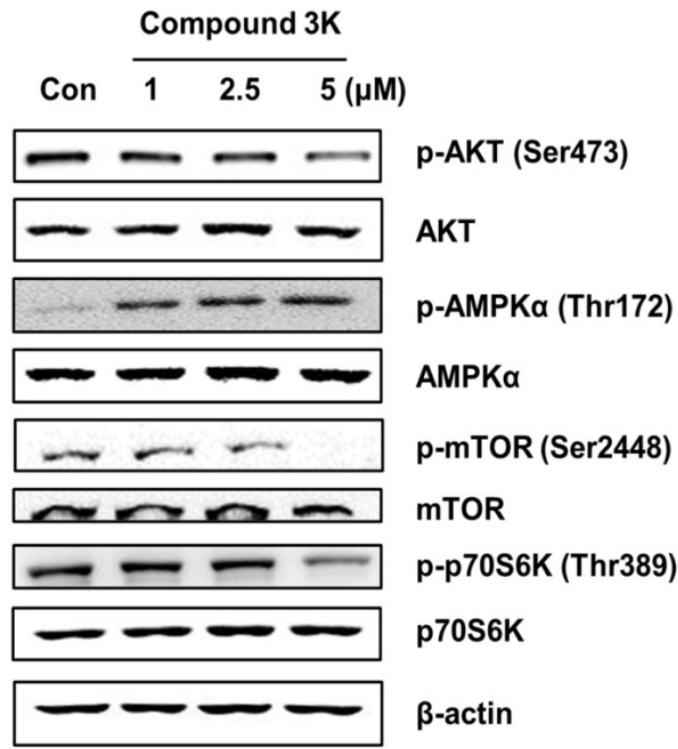

B
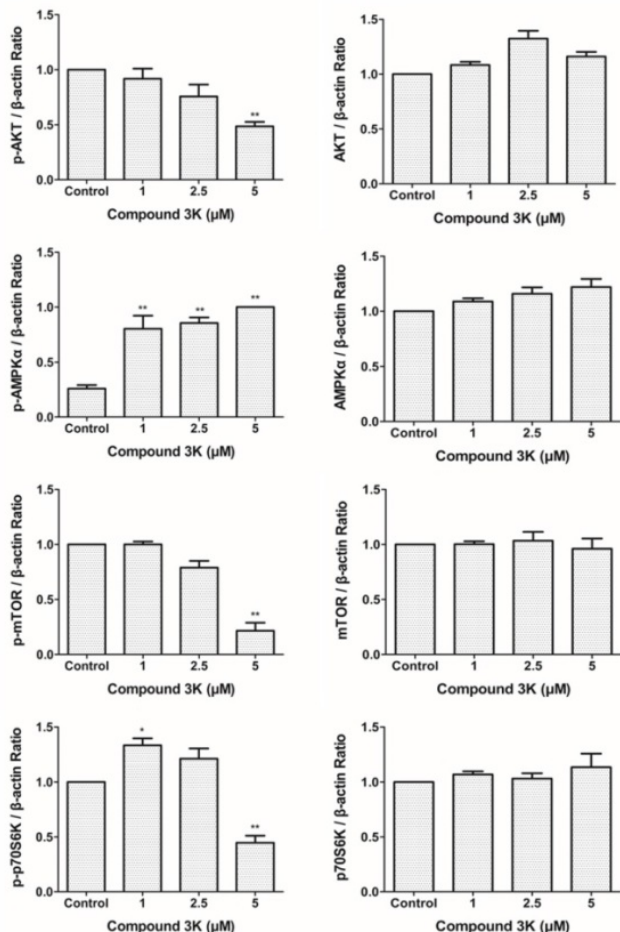

Figure 7. Changes in the expression of various proteins in signaling pathways following PKM2 inhibition by compound $3 \mathrm{~K}$ for $24 \mathrm{~h}$. (A) The effect of PKM2 inhibition on signaling pathways in SK-OV-3 cells. Cells were treated with compound 3K, and western blot analysis was conducted to determine the expression levels of various signaling pathway proteins. (B) The band intensity of Akt, p-Akt, AMPK, p-AMPK, mTOR, p-mTOR, p70S6K, and p-p70S6K were calculated and expressed in the graph as a ratio of $\beta$-actin. The values represent the mean $\pm S D$. ${ }^{*} p<0.05$ and $*^{*} p<0.01$.

A

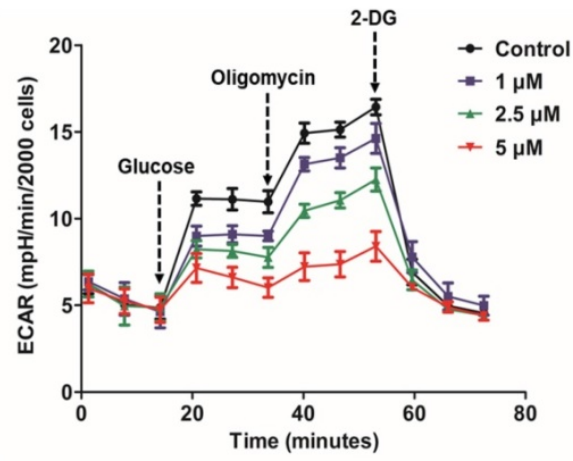

C

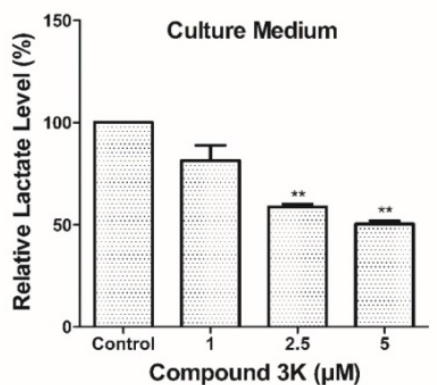

B

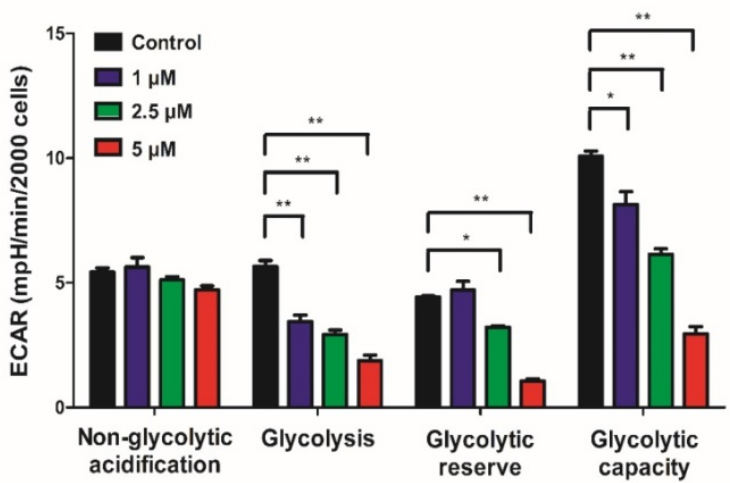

D

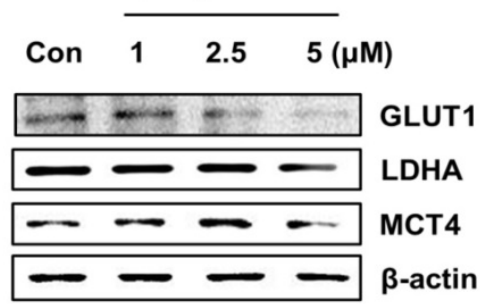

Figure 8. Compound $3 \mathrm{~K}$ altered glycolytic function in SK-OV-3 cells. (A) The level of ECAR was measured using XF Glycolytic Stress Test kit. Following incubation for $24 \mathrm{~h}$, compound $3 \mathrm{~K}(1,2.5$, or $5 \mu \mathrm{M})$ was added to the plates followed by treatment with $15 \mathrm{mM}$ glucose, $2 \mu \mathrm{M}$ oligomycin, and $50 \mathrm{mM} 2-\mathrm{DG}$ subsequently. (B) Quantification of glycolytic function in SK-OV-3 cells following treatment. (C) Quantitative level of lactate in the culture media of compound 3K-treated cells. (D) Western blot analysis was performed to determine the protein expression levels of GLUT-1, LDHA, and MCT-4. The values represent the mean \pm SD. *p $<0.05$ and ** $<<0.01$. 
A

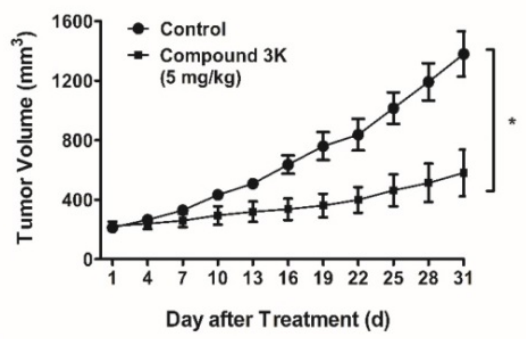

D

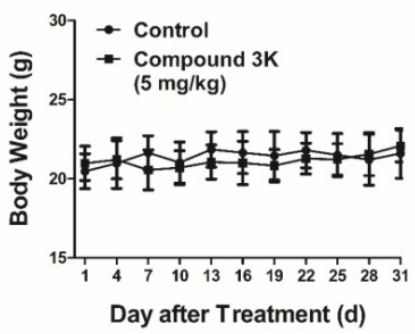

B

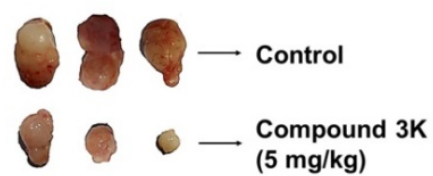

E

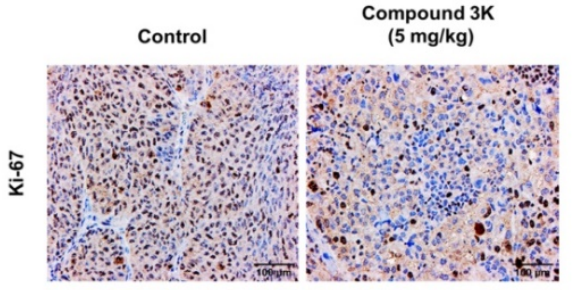

C

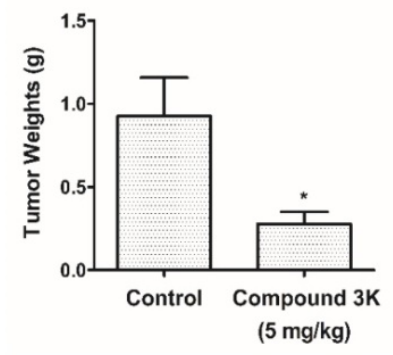

Figure 9. Compound 3K inhibited SK-OV-3 cell tumorigenesis in vivo. Compound $3 \mathrm{~K}$ exhibited therapeutic effect on ovarian cancer in a tumor xenograft model. BALB/c nude mouse were divided into two groups randomly ( $\mathrm{n}=5$ per group) and administered with vehicle or compound $3 \mathrm{~K}(5 \mathrm{mg} / \mathrm{kg})$ orally. Tumor size was calculated every three days for 31 days before the mice were sacrificed. (A) Changes in tumor volume. (B) Photographs of the tumors. (C) Comparison of tumor weight between compound $3 \mathrm{~K}$ group and control group. (D) Changes of body weight. (E) Immunohistochemical analysis using an anti-Ki-67 antibody and its quantification (Magnification $\times 100)$. The values represent the mean \pm SD. $*_{p}<0.05$ and $*^{*} p<0.01$.

Although siRNA-PKM2 markedly inhibited cell proliferation and migration, induced apoptosis, and caused cell cycle arrest in SK-OV-3 cells overexpressing PKM2 [14], the clinical application of siRNA therapy is limited. Therefore, to identify PKM2-targeted therapeutic drugs for potential clinical application, we evaluated the effects of compound $3 \mathrm{~K}$ in SK-OV-3 cells, a specific inhibitor of PKM2 [15]. We investigated the mechanisms and in vivo toxicity of compound $3 \mathrm{~K}$ in SK-OV-3 cells, a well-established human epithelial adenocarcinoma cell line model that is resistant to several cytotoxic drugs such as cis-platinum, diphtheria toxin, and adriamycin [18]. We believe that our results will provide a basis for the application of PKM2 inhibitors in the treatment of advanced stages of ovarian cancer.

Specifically, we found that treatment with compound $3 \mathrm{~K}$ markedly decreased the proliferation of SK-OV-3 cells in a dose and time-dependent manners, suggesting a relationship between the overexpression of PKM2 and ovarian cancer cell survival. A previous study reported that the knockdown of PKM2 in HeLa and SiHa cells at different cell cycle phases resulted in an increase in the percentage of cells in the G2/M phase. PKM2 knockdown increased DNA damage and G2/M cell cycle arrest following p53 activation, and thereby enhanced the radiosensitivity of the cells [28]. In this study, treatment with compound $3 \mathrm{~K}$ caused an arrest of the cells at the G2/M phase, which was mediated by an increase in the expression of p-Cdc2. Moreover, PKM2 plays an important role in the pathways associated with metastasis [6]. SiRNA-mediated knockdown of PKM2 resulted in an upregulation of tumor suppressors, including Bad, caspase 7 , and E-cadherin, whereas oncogenes, such as MMP-2, MMP-9, HIF1a, and VEGF, were downregulated in the SK-OV-3 cells [14]. MMP-2 and MMP-9, which belong to the MMP family, are closely associated with the metastasis of tumor cells $[29,30]$.

Akt-mTOR signaling is a major negative regulatory pathway of autophagy $[19,31]$. Akt, the serine/threonine protein kinase, is associated with mTOR activity and positively regulates mTOR, which is a major protein in the regulation of autophagy [32]. As a central control molecule, mTOR accepts signals from growth factors, nutrients, and many kinases including AMPK. The phosphorylation of AMPK induces a downstream signal that inhibits $\mathrm{MTOR}$ and activates autophagy, leading to the induction of catabolic processes [33]. The phosphorylation of mTOR increases the expression of downstream proteins, such as $\mathrm{p} 70 \mathrm{~S} 6 \mathrm{~K}$, to control various cellular processes. The phosphorylation of p70S6K is necessary for the induction of translation of proteins associated with proliferation and growth [34]. Our 
data demonstrated that compound $3 \mathrm{~K}$ regulated the Akt/AMPK/mTOR signaling pathway in SK-OV-3 cells. A previous study has shown that the knockdown of PKM2 activated AMPK signaling in response to the disturbed energy metabolism in H1299 cells. PKM2 knockdown increased AMPK phosphorylation at Thr172 and decreased p70S6K phosphorylation at Thr389. A549 cells that failed to induce AMPK signaling in response to PKM2 knockdown experienced apoptotic cell death but not autophagy. These results demonstrate the importance of AMPK signaling in cancer cell survival following energy disturbance caused by PKM2 inhibition [35].

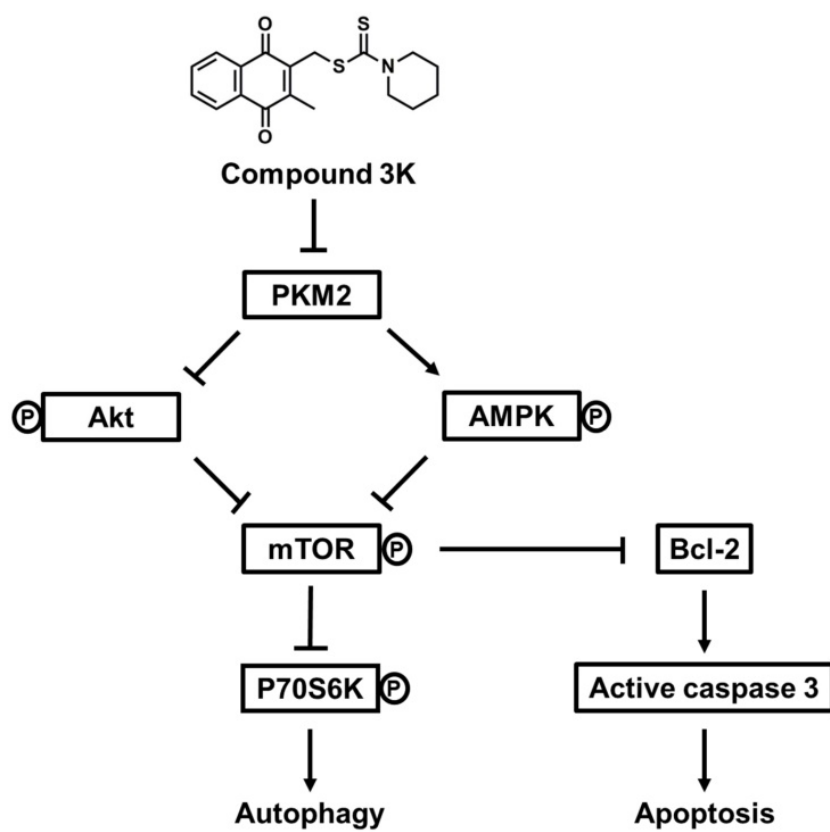

Figure 10. Schematic diagram illustrating potential pathways associated with cell death in compound 3K-treated SK-OV-3 cells. Compound $3 \mathrm{~K}$-induced cell death is associated with the Akt/AMPK/mTOR signaling pathway. Compound 3K induces phosphorylation of AMPK at Thr172 and reduces the phosphorylation of Akt. These molecular changes cause the suppression of mTOR signaling, thereby regulating autophagy and apoptosis.

Autophagy and apoptosis are crucial cellular processes that maintain cell homeostasis, and both processes are connected in many ways. Autophagy and apoptosis are coupled by the interaction of Bcl-2 and Beclin-1 [36]. The Bcl-2 family is a major regulator of apoptotic signaling associated with pro- and anti-apoptotic members. The post-translational phosphorylation of Akt, mTOR, and p70S6K regulates Bcl-2 activation [37]. Beclin-1, also known as the mammalian orthologue of yeast Atg6, is involved in the nucleation of the autophagosomal membrane. In cells, the Bcl-2 family plays anti-apoptotic roles [38]. Beclin-1 binds to the proteins of the Bcl-2 family through a BH3 domain, and autophagy is activated by the release of Bcl-2 from Beclin-1 [39]. PKM2 knockdown influences the interaction between the members of Bcl-2 family and Beclin-1, which may be accompanied by a decreased expression level of Bcl-2. A previous study showed that PKM2 knockdown activates autophagy and apoptotic signals in A549, an alveolar adenocarcinoma cell line [17]. Our study also demonstrated that the PKM2 inhibitor, compound 3K, induced autophagy and apoptosis in SK-OV-3 cells.

In summary, our study indicated that compound 3K markedly inhibited glycolytic function and tumor growth in SK-OV-3 cells. Compound 3K markedly reduced the expression levels of GLUT1, LDHA, and MCT4, which may have inhibited glucose uptake, pyruvate conversion, and lactate efflux, respectively. Moreover, compound 3K treatment suppressed tumor growth and mass without significant body weight changes in the tumor xenograft mice. Collectively, our study demonstrated that compound $3 \mathrm{~K}$, a specific PKM2 inhibitor, inhibited SK-OV-3 cell growth and glycolytic function through autophagy and apoptosis mediated by the Akt/AMPK/mTOR signaling pathway (Figure 10).

\section{Abbreviations}

PKM2: pyruvate kinase M2; PKM1: pyruvate kinase M1; MTT: 3-(4,5-dimethylthiazol-2-yl)-2,5diphenyltetrazolium bromide; mTOR: mechanistic target of rapamycin; ATP: adenosine triphosphate; AKT1: AKT serine/threonine kinase 1; siPKM2: small interfering pyruvate kinase M2; PVDF: polyvinylidene difluoride; DMSO: dimethylsulfoxide; DAPI: 4',6-diamidino-2-phenylindole; LC: liquid chromatography; ANOVA: analysis of variance; IHC: immunohistochemistry; siRNA: small interfering ribonucleic acid; PBS: phosphate-buffered saline; GLUT1: glucose transporter 1; LDHA: lactate dehydrogenase A; MCT4: monocarboxylate transporter 4; RPMI: roswell park memorial institute medium; MMP: matrix metalloprotease; TIMP2: tissue inhibitor of metalloproteinases 2.

\section{Acknowledgements}

This work was funded by the National Research Foundation (NRF) of Korea (grant number NRF2019R1A2C2002923).

\section{Author Contributions}

All authors were involved in the development of the study protocol and the experimental design. All authors read, commented on, and contributed to the submitted manuscript. Experiments were performed by J.H.P, A.K, S.H.L, C.J, Y.S.K, S.Y.K, and S.H.P. Data were analyzed by J.H.P and S.H.L. The manuscript was written by J. H. P. and finalized by H.S.K. 


\section{Competing Interests}

The authors have declared that no competing interest exists.

\section{References}

1. Siegel RL, Miller KD, Jemal A. Cancer statistics, 2019. CA Cancer J Clin. 2019;69(1):7-34.

2. Baldwin LA, Huang B, Miller RW, et al. Ten-year relative survival for epithelial ovarian cancer. Obstet Gynecol. 2012;120(3):612-8.

3. Chen XS, Li LY, Guan YD, et al. Anticancer strategies based on the metabolic profile of tumor cells: therapeutic targeting of the Warburg effect. Acta Pharmacol Sin. 2016;37(8):1013-9.

4. Tamada M, Suematsu M, Saya H. Pyruvate kinase M2: multiple faces for conferring benefits on cancer cells. Clin Cancer Res. 2012;18(20):5554-61.

5. Dong G, Mao Q, Xia W, et al. PKM2 and cancer: the function of PKM2 beyond glycolysis. Oncol Lett. 2016;11(3):1980-6.

6. Zahra K, Dey T, et al. Pyruvate kinase M2 and cancer: the role of PKM2 in promoting tumorigenesis. Front Oncol. 2020;10:159.

7. Yang W, Lu Z. Pyruvate kinase M2 at a glance. J Cell Sci. 2015;128(9):1655-60

8. He CL, Bian YY, Xue Y, et al. Pyruvate kinase M2 activates mTORC1 by phosphorylating AKT1S1. Sci Rep. 2016;6:21524.

9. Su Q, Luo $\mathrm{S}$, Tan $\mathrm{Q}$, et al. The role of pyruvate kinase M2 in anticancer therapeutic treatments. Oncol Lett. 2019;18(6):5663-72.

10. Spoden GA, Mazurek S, Morandell D, et al. Isotype-specific inhibitors of the glycolytic key regulator pyruvate kinase subtype M2 moderately decelerate tumor cell proliferation. Int I Cancer. 2008;123(2):312-21.

11. Dey P, Kundu A, Sachan R, et al. PKM2 knockdown induces autophagic cell death via AKT/mTOR pathway in human prostate cancer cells. Cell Physiol Biochem. 2019;52(6):1535-52.

12. Dey P, Son JY, Kundu A, et al. Knockdown of pyruvate kinase M2 inhibits cell proliferation, metabolism, and migration in renal cell carcinoma. Int J Mol Sci. 2019;20(22):5622

13. Spoden GA, Rostek U, Lechner S, et al. Pyruvate kinase isoenzyme M2 is a glycolytic sensor differentially regulating cell proliferation, cell size and apoptotic cell death dependent on glucose supply. Exp Cell Res. 2009:315(16):2765-74

14. Miao Y, Lu M, Yan Q, et al. Inhibition of proliferation, migration, and invasion by knockdown of pyruvate kinase-M2 (PKM2) in ovarian cancer SKOV3 and OVCAR3 cells. Oncol Res. 2016;24(6):463-75.

15. Ning $\mathrm{X}, \mathrm{Qi} \mathrm{H}, \mathrm{Li} \mathrm{R}$, et al. Discovery of novel naphthoquinone derivatives as inhibitors of the tumor cell specific M2 isoform of pyruvate kinase. Eur J Med Chem. 2017;138:343-52.

16. Chao TK, Huang TS, Liao YP, et al. Pyruvate kinase M2 is a poor prognostic marker of and a therapeutic target in ovarian cancer. PLoS One. 2017;12(7):e0182166.

17. Chu B, Wang J, Wang Y, et al. Knockdown of PKM2 induces apoptosis and autophagy in human A549 alveolar adenocarcinoma cells. Mol Med Rep. 2015;12(3):4358-63

18. Yan XD, Li M, Yuan Y, et al. Biological comparison of ovarian cancer resistant cell lines to cisplatin and Taxol by two different administrations. Oncol Rep. 2007;17(5):1163-9.

19. Sachan R, Kundu A, Jeon Y, et al. Afrocyclamin A, a triterpene saponin, induces apoptosis and autophagic cell death via the PI3K/Akt/mTOR pathway in human prostate cancer cells. Phytomedicine. 2018;51:139-50.

20. Peery R, Kyei-Baffour K, Dong Z, et al. Synthesis and identification of a novel lead targeting survivin dimerization for proteasome-dependent degradation. J Med Chem. 2020;63(13):7243-51.

21. Tan KT, Chen PW, Li S, et al. Pterostilbene inhibits lung squamous cell carcinoma growth in vitro and in vivo by inducing $\mathrm{S}$ phase arrest and apoptosis. Oncol Lett. 2019;18(2):1631-40.

22. Hsu MC, Hung WC. Pyruvate kinase M2 fuels multiple aspects of cancer cells: from cellular metabolism, transcriptional regulation to extracellular signaling. Mol Cancer. 2018;17(1):35.

23. Yeung TL, Leung CS, Yip KP, et al. Cellular and molecular processes in ovarian cancer metastasis. A review in the theme: cell and molecular processes in cancer metastasis. Am J Physiol Cell Physiol. 2015;309(7):C444-56.

24. Munafó DB, Colombo MI. A novel assay to study autophagy: regulation of autophagosome vacuole size by amino acid deprivation. J Cell Sci. 2001;114(Pt 20):3619-29.

25. Zhu H, Luo H, Zhu X, et al. Pyruvate kinase M2 (PKM2) expression correlates with prognosis in solid cancers: a meta-analysis. Oncotarget. 2017;8(1):162840 .

26. Wang C, Jiang J, Ji J, et al. PKM2 promotes cell migration and inhibits autophagy by mediating $\mathrm{PI} 3 \mathrm{~K} / \mathrm{AKT}$ activation and contributes to the malignant development of gastric cancer. Sci Rep. 2017;7(1):2886.

27. Li X, Deng S, Liu M, et al. The responsively decreased PKM2 facilitates the survival of pancreatic cancer cells in hypoglucose. Cell Death Dis. 2018;9(2):133.

28. Lin $\mathrm{Y}$, Zhai $\mathrm{H}$, Ouyang $\mathrm{Y}$, et al. Knockdown of PKM2 enhances radiosensitivity of cervical cancer cells. Cancer Cell Int. 2019:19:129.
29. Quintero-Fabián S, Arreola R, Becerril-Villanueva E, et al. Role of matrix metalloproteinases in angiogenesis and cancer. Front Oncol. 2019;9:1370.

30. Burger GA, Danen EHJ, Beltman JB. Deciphering epithelial-mesenchymal transition regulatory networks in cancer through computational approaches. Front Oncol. 2017;7:162.

31. Yu Y, Hou L, Song H, et al. Akt/AMPK/mTOR pathway was involved in the autophagy induced by vitamin E succinate in human gastric cancer SGC-7901 cells. Mol Cell Biochem. 2017;424(1-2):173-83.

32. Porta C, Paglino C, Mosca A. Targeting PI3K/Akt/mTOR signaling in cancer. Front Oncol. 2014;4:64

33. Li W, Saud SM, Young MR, et al. Targeting AMPK for cancer prevention and treatment. Oncotarget. 2015;6(10):7365-78

34. Chen HY, White E. Role of autophagy in cancer prevention. Cancer Prev Res (Phila). 2011:4(7):973-83.

35. Prakasam G, Singh RK, Iqbal MA, et al. Pyruvate kinase $M$ knockdown-induced signaling via AMP-activated protein kinase promotes mitochondrial biogenesis, autophagy, and cancer cell survival. J Biol Chem. 2017;292(37):15561-76.

36. Maiuri MC, Criollo A, Kroemer G. Crosstalk between apoptosis and autophagy within the Beclin 1 interactome. EMBO J. 2010;29(3):515-6.

37. Johnstone RW, Ruefli AA, Lowe SW. Apoptosis: a link between cancer genetics and chemotherapy. Cell. 2002;108(2):153-64.

38. Dietrich JB. Apoptosis and anti-apoptosis genes in the Bcl-2 family. Arch Physiol Biochem. 1997;105(2):125-35.

39. Sinha S, Colbert CL, Becker N, et al. Molecular basis of the regulation of Beclin 1-dependent autophagy by the gamma-herpesvirus 68 Bcl-2 homolog M11. Autophagy. 2008;4(8):989-97. 